\title{
Research on Water Quality in Dahuofang Reservoir Based on Fuzzy Comprehensive Evaluation
}

\author{
Lingling Ma \\ Shenyang Agricultural University \\ Shenyang, China \\ damaling@126.com \\ Tieliang Wang \\ Shenyang Agricultural University \\ Shenyang, China \\ tieliangwang@126.com
}

\author{
Linfei Zhou \\ Shenyang Agricultural University \\ Shenyang, China \\ zlf924@163.comt \\ LiangLi \\ Shenyang Agricultural University \\ Shenyang, China \\ liliang19810819@163.com
}

\begin{abstract}
Based on fuzzy comprehensive evaluation, it evaluates the water quality of Dahuofang Reservoir and selects 7 monitoring sections and six major pollution factors for the study object. The result demonstrates that Hun River is the most seriously polluted in three storage of Dahuofang Reservoir inflow,which is determined IV grade,She River and TaiGou are determined IIIgrade, The water quality of reservoir is mainly II grade except the tail. The quality of outflow is II grade.Reservoir is mainly affected by nitrogen and phosphorus nutrient pollution.
\end{abstract}

Keywords-fuzzy comprehensive evaluation; membership degree; Dahuofang Reservoir

\section{INTRODUCTION}

Dahuofang reservoir provides domestic water and industrial water for the seven cities in Liaoning Province,and is the main water source in the central cities of Liaoning Province, which plays an important strategic position.Recent years, the content of total nitrogen and phosphorus have long been at a high level.With the large number of application of fertilizer and pesticide in Dahuofang reservoir catchment area, significant emissions of domestic sewage and industrial wastewater,and with increased a greater amount of additional production and living facilities, which destructs surface vegetation, and increases non-point source pollution in the watershed. Therefore,it is particularly important to make intuitive water quality evaluation.

Currently, there are many water quality evaluation methods, such as fuzzy comprehensive evaluation method [1-3] 、 comprehensive index evaluation method principal component analysis ${ }^{[4]}$ 、 artificial neural network model, genetic algorithm $^{[5]}$ 、 gray clustering method ${ }^{[6]}$ and so on. Fuzzy mathematics was founded in 1965 by the professor Chad who is a mathematician and cybernetics expert of University of California. In recent years, fuzzy mathematics has been widely applied in water quality evaluation $^{[7]}$. Water environment quality has the overall heterogeneity and the relative instability of the local area. Therefore it can be seen as a vague concept ${ }^{[8]}$.In the field of water quality evaluation, there are many scholars using of such method to application analysis, Fuzzy comprehensive evaluation method is applied to the reservoir, river, ocean water quality evaluation byZhao Xiaoliang, Xie Qun and Song Ke ${ }^{[9-11]}$ In this paper, fuzzy comprehensive evaluation will be used to evaluate the water quality of Dahuofang Reservoir.

\section{FUZZY COMPREHENSIVE EVALUATION MATHEMATICAL MODEL}

\section{A. Introduction of fuzzy Comprehensive Evaluation}

Fuzzy comprehensive evaluation method is a way of assessment of water quality of the environment using the principle of fuzzy mathematics. It is a method to determine the water level by the membership degree which is determined by the measured sample sequence and the standard sequence of levels. This method takes into account the position of various factors participated in the evaluation, with appropriate weights for the factors, and determins membership functions. After fuzzy matrix composite operations, comprehensive membership will be obtained. According to the comprehensive membership to divide of of water quality, and then we can get comprehensive evaluation results.

\section{B. Specific steps of fuzzy comprehensive evaluation}

1) Supposed that the measured indicator set is $U, U$ obtains $n$ water samples, and each sample contains $m$ evaluation indexes.

2) Determine the membership functions which means that the various factors belong to the degree of all kinds of water quality level

Based on water quality standards at all levels of the ground water quality standards, Establishment of water each factor of quality evaluation corresponding to the 
membership function of different levels of water quality [12].

For the first level water, i.e.j=1, the membership function is

$$
U_{j}=\left\{\begin{array}{lc}
1 & C_{i}<S_{j} \\
S_{j+1}-C_{i} & S_{j}<C_{i}<S_{j+1} \\
\frac{S_{j+1}-S_{j}}{0} & C_{i} \geq S_{j-1}
\end{array}\right.
$$

For the second to forth level water,i.e.j=2-4, the membership function is

$$
U_{j}=\left\{\begin{array}{cc}
1 & C_{i}=S_{j} \\
C_{i}-S_{j-1} & S_{j-1}<C_{i}<S_{j} \\
S_{j}-S_{j-1} & S_{j}<C_{i}<S_{j+1} \\
S_{j+1}-C_{i} & C_{i}>S_{j}+1 \\
\hline S_{j+1}-S_{j} & \\
0 &
\end{array}\right.
$$

For the fifth level water, i.e.j=5, the membership function is

$$
U_{j}=\left\{\begin{array}{cc}
1 & C_{i} \geq S_{j} \\
C_{i}-S_{j-1} & S_{j-1}<C_{i}<S_{j} \\
\hline S_{j}-S_{j-1} & C_{i} \leq S_{j-1} \\
0 &
\end{array}\right.
$$

$\mathrm{C}_{\mathrm{i}}$ is the measured concentration values of the ith evaluation factor,

$S_{j}, S_{i-1}$ and $S_{i+1}$ are the $j$ th,$j-1$ th and $j+1$ th water quality standard value of the evaluation factor.

3) Determine the index weight

The role of different water quality indicators of environmental pollution is not only concerned with their size of measured data,but also with the allowed certain concentration of the standard of various indicators in some uses of water. The indicators with same measured data, have big concentrations of the standard, will have less impact on the degree of pollution. So the formula of normalized weights is: $\mathrm{W}_{\mathrm{i}}=\frac{\mathrm{C}_{\mathrm{i}}}{\mathrm{S}_{\mathrm{i}}} / \sum_{\mathrm{i}=1}^{\mathrm{n}} \frac{\mathrm{C}_{\mathrm{i}}}{\mathrm{S}_{\mathrm{i}}}$

In the formula, $\mathrm{C}_{\mathrm{i}}$ is the measured concentration of the ith indicator, $S_{i}$ is the average of five standard values of the evaluation factor.

4) Fuzzy matrix composite operator

Based on the above factor's weight and the matrix, get the membership required by evaluation after the calculated.

$$
\mathrm{B}=\mathrm{U}_{\mathrm{m} \times \mathrm{n}} \cdot \mathrm{W}_{\mathrm{i}}
$$

5) Using ranking characteristic value to determine the water quality level

When the maximum degree of membership principles do not apply,we use characteristic values to determine the level of water quality

$$
\mathbf{H}=\sum_{\mathbf{h}=1}^{\mathrm{c}} \mathrm{b} \square \mathrm{h}
$$

In the formula, $\mathrm{H}$ is the features of classification, $\mathrm{b}$ is relative menbership degree, h is water quality level,c is the number of water quality classification

\section{COMPREHENSIVE EVALUATION OF WATER QUALITY IN DAHUOFANG RESERVOIR}

\section{A. The study area profile}

Dahuofang reservior is located in the upper reaches of the Hun River,and is the one of the national key water sources. The reservior controls drainage area $5437 \mathrm{~km}^{2}$, the largest capacity is 2.187 billion $\mathrm{m}^{3}$, length of the reservoir is $35 \mathrm{~km}$, its width of the widest is $4 \mathrm{~km}$, and the narrowest is $0.3 \mathrm{~km}$. For the general,wide south-north,and narrow east-west. The reservoir has large amount of reservoir water exchange, and is mainly composed of the Hun River、Suzi River and She River. It is the large-scale project for flood control, irrigation, industrial and urban domestic water,and power generation, fish farming and tourism. Currently, the reservoir is contaminated by nonpoint source pollution of the surrounding watershed, agriculture and livestock pollution. In this paper,we select 7 monitoring sections of Dahuofang reservior,they are respectively,inbound mouths:Taigou(She River) 、 Gulou(Suzi River)、Beizamu(Hun River); the reservoir area : Hun37(middle of reservoir) 、 Hun73(tail of reservoir) 、 Hun7(front of reservoir); outbound mouth:Fushun intake.

\section{B. Determine the evaluation indexes, evaluation sets and the matrixes of membership degree}

Annual monitoring indicators of Dahuofang Reservior are about 30 items. The selected indicators according to the water feature are: $\mathrm{DO} 、 \mathrm{BOD}_{5} 、 \mathrm{CODmn} 、 \mathrm{NH}_{3}-\mathrm{N} 、 \mathrm{TN}$ 、 TP. The annual average of water quality monitoring

\begin{tabular}{|c|c|c|c|c|c|c|}
\hline \multirow{2}{*}{ Section } & \multicolumn{6}{|c|}{ Evaluation Index (mg.L $\left.{ }^{-1}\right)$} \\
\hline & $D O$ & $\operatorname{Cod}_{\operatorname{man}}$ & $\mathrm{BOD}_{5}$ & $\mathrm{NH}_{3}-\mathrm{N}$ & $T N$ & $T P$ \\
\hline Taigou(She river) & 9.80 & 2.40 & 1.45 & 0.17 & 1.55 & 0.02 \\
\hline Beizamu(Hun river) & 10.20 & 3.10 & 1.85 & 0.252 & 2.37 & 0.02 \\
\hline Gulou(Suzi river) & 10.90 & 2.50 & 1.96 & 0.168 & 1.57 & 0.018 \\
\hline Hun7(front of reservoir) & 9.60 & 2.90 & 1.70 & 0.105 & 1.24 & 0.01 \\
\hline Hun37(middle of reservoir) & 9.10 & 2.20 & 1.10 & 0.15 & 1.00 & 0.01 \\
\hline Hun73(tail of reservoir) & 9.20 & 2.10 & 1.50 & 0.125 & 1.03 & 0.01 \\
\hline $\begin{array}{l}\text { Fushun intake (outbound } \\
\text { mouth) }\end{array}$ & 10.00 & 2.00 & 1.30 & 0.135 & 0.98 & 0.01 \\
\hline
\end{tabular}
sections shows in table 1 . According to $\leq$ Surface Water Quality Standards $\geq\left(\right.$ GB3838-2002) ${ }^{[13]}$, establish the

\begin{tabular}{|c|c|c|c|c|c|c|}
\hline \multirow{2}{*}{ Evaluation level } & \multicolumn{6}{|c|}{ Evaluation Index $\left(\mathrm{mg} \cdot \mathrm{L}^{-1}\right)$} \\
\hline & DO. & $\mathrm{Cod}_{\max .7}$ & $B O D_{5.1}$ & $\mathrm{NH}_{3}-\mathrm{N} .1$ & $T N .1$ & $T P .1$ \\
\hline I. & 7.5 .1 & 2.1 & 3.1 & 0.15 & 0.2 .2 & 0.01 \\
\hline II . . & 6. & 4. & 3.1 & 0.5. & 0.5. & 0.025 \\
\hline III.. & 5.1 & 6.7 & 4.1 & 1.1 & 1.7 & 0.05 \\
\hline $\mathrm{N}$. & 3.7 & 10. & 6. & 1.5. & 1.5 .1 & 0.1. \\
\hline $\mathrm{V} . \mathrm{I}$ & 2.1 & 15.1 & 10. & 2.1 & 2.1 & 0.2 .1 \\
\hline
\end{tabular}
indicators' evaluation criterias which show in table 2.

TABLE I. MAIN EVALUATION' MONITORING DATA OF

TABLE II. WATER QUALITY EVALUATION CRITERIA 
Water quality standards were divided into 5 grades, I grade corresponding to the highest standards of water quality levels achieves drinking water quality requirements, just pay attention to maintaining and protecting water resources; II and III grade level standards corresponding to good water quality, we need to manage and protect water sources, and achieve water security requirements; IV and $\mathrm{V}$ grade corresponds poor water level, we need to take certain measures to improve water quality conditions and to achieve safe drinking water requirements.

Take the annual average of monitoring data of each section into corresponding membership functions, and membership matrix obtained as follows:

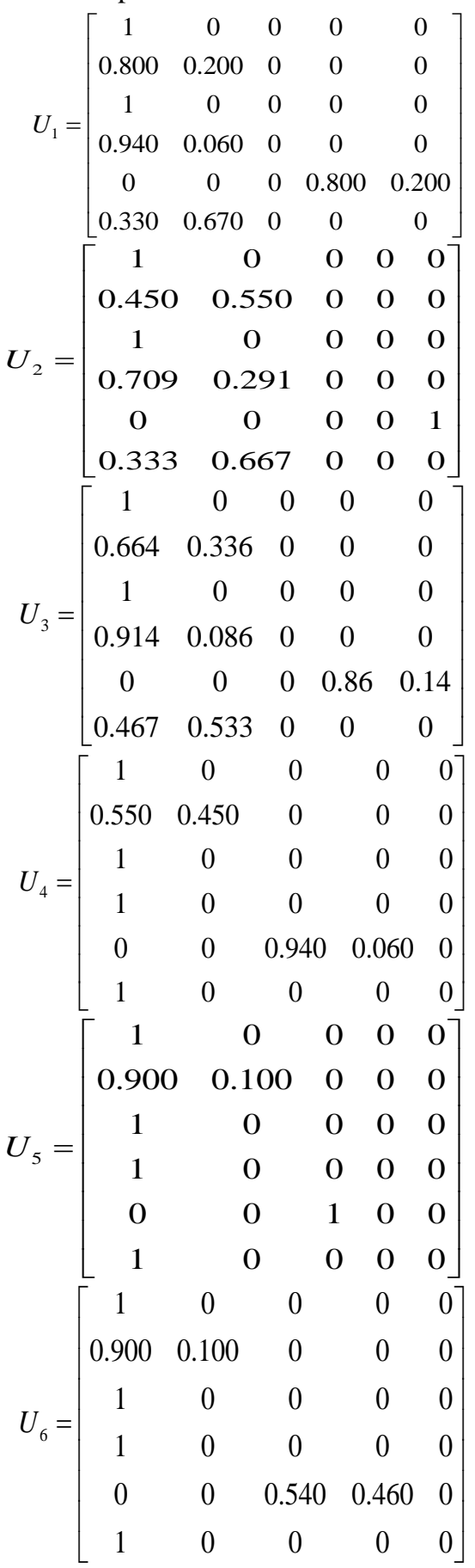

$$
U_{7}=\left[\begin{array}{ccccc}
1 & 0 & 0 & 0 & 0 \\
0.950 & 0.050 & 0 & 0 & 0 \\
1 & 0 & 0 & 0 & 0 \\
1 & 0 & 0 & 0 & 0 \\
0 & 0.04 & 0.96 & 0 & 0 \\
1 & 0 & 0 & 0 & 0
\end{array}\right]
$$

\section{Conform the weight}

According to the formula to calculate weights, and then to normalize,the results show in table3:

TABLE III. THE MONITORING INDICATORS' NORMALIZED WEIGHTS

\begin{tabular}{|c|c|c|c|c|c|c|c|}
\hline \multirow{2}{*}{ No. } & \multirow{2}{*}{ section } & \multicolumn{6}{|c|}{ Evaluation Index } \\
\hline & & $D O$ & $C O D_{m n}$ & $\mathrm{BOD}_{5}$ & $\mathrm{NH}_{3}-\mathrm{N}$ & $T N$ & $T P$ \\
\hline \multirow{2}{*}{$\begin{array}{l}1 \\
2\end{array}$} & Taigou(She river) & 0.160 & 0.108 & 0.093 & 0.055 & 0.497 & 0.087 \\
\hline & Beizamu(Hun river) & 0.115 & 0.104 & 0.089 & 0.061 & 0.567 & 0.065 \\
\hline \multirow[b]{2}{*}{4} & Gulou(Suzi river) & 0.141 & 0.110 & 0.127 & 0.053 & 0.493 & 0.076 \\
\hline & Hun7(front of reservoir) & 0.202 & 0.162 & 0.135 & 0.042 & 0.405 & 0.054 \\
\hline 5 & Hun37(middle of reservoir) & 0.228 & 0.131 & 0.094 & 0.064 & 0.425 & 0.057 \\
\hline \multirow[b]{2}{*}{7} & Hun73(tail of reservoir) & 0.203 & 0.113 & 0.115 & 0.048 & 0.470 & 0.052 \\
\hline & $\begin{array}{l}\text { Fushun intake } \\
\text { (outbound mouth) }\end{array}$ & 0.214 & 0.123 & 0.114 & 0.060 & 0.430 & 0.059 \\
\hline
\end{tabular}
OF EACH SECTION

\section{Composite calculation of fuzzy matrix and normalize} the results

$\mathrm{B}_{1}=\left(\begin{array}{lll}0.166,0.112,0,0.515,0.207\end{array}\right)$

$\mathrm{B}_{2}=(0.146,0.132,0,0,0.721)$

$\mathrm{B}_{3}=(0.141,0.110,0,0.493,0.14)$

$\mathrm{B}_{4}=(0.244,0.195,0.489,0.072,0)$

$\mathrm{B}_{5}=(0.303,0.133,0.564,0,0)$

$\mathrm{B}_{6}=(0.165,0.081,0.381,0.373,0)$

$\mathrm{B}_{7}=(0.308,0.072,0.62,0,0)$

Composite calculation results show that the maximum memberships of $\mathrm{B}_{3} 、 \mathrm{~B}_{4} 、 \mathrm{~B}_{6} 、 \mathrm{~B}_{7}$ are all less than 0.5 ,so ,it is not apply to maximum membership degree principle.

\section{E. Determin the level of water quality}

According to the formula to calculate the corresponding ranking characteristic value, and based on the value to classify the sample.

Taigou section as an example:

$\mathrm{H}=0.166 * 1+0.112 * 2+0.515 * 4+0.207 * 5=3.485$

Between III and IV grade,close to IIIgrade, therefore, the determination of the level of water is III grade.The water quality level of each section shows in table 4: 
TABLE IV. THE EVALUATION RESULTS

\begin{tabular}{|c|c|c|}
\hline section & $\begin{array}{c}\text { ranking characteristic } \\
\text { value }\end{array}$ & $\begin{array}{c}\text { the level of } \\
\text { water quality }\end{array}$ \\
\hline Taigou(She river) & 3.485 & III \\
\hline Beizamu(Hun river) & 4.015 & IV \\
\hline Gulou(Suzi river) & 3.999 & III \\
\hline Hun7(front of reservoir) & 2.389 & II \\
\hline $\begin{array}{l}\text { Hun37(middle of } \\
\text { reservoir) }\end{array}$ & 2.261 & II \\
\hline Hun73(tail of reservoir) & 2.963 & III \\
\hline $\begin{array}{l}\text { Fushun intake } \\
\text { (outbound mouth) }\end{array}$ & 2.312 & II \\
\hline
\end{tabular}

It evaluated the water quality of Dahuofang Reservoir based on fuzzy comprehensive evaluation, SheRiver and Suzi River are III grade among the reservior inflow, HunRiver are IV grade, the pollution is serious, mainly nitrogen pollution. In the reservoir,Hun 73 section is III grade,Hun7 and Hun37 sections are II grade, the overall water quality is good,but total nitrogen content is high. The quality of outflow is II grade.

\section{CONCLUTION}

Due to the interconnection of the extent of water pollution and water quality classification, and there is ambiguity, and the changes in water quality is continuous.so, fuzzy evaluation method in theory has a certain rationality.Based on the fuzzy comprehensive evaluation method, water quality assessment uses of membership degree to describe classification, in line with the multi-index, multi-level features in the evaluation of water quality,reflects the water quality objectively. The results show that this method is simple, real results are reliable, the evaluation method is applicable. Through the quality evaluation, water quality management program can be proposed.

After analysis of six contaminated factors on seven main monitoring sections of Dahuofang reservoir 2012,we concludes that the major pollutants of Dahuofang is nitrogen pollution, and it exists utrophication risks.and should strengthen the control of agricultural non-point source pollution, reduce the pesticide 、 fertilizer 、 livestock manure storage and stacking to bring the load to reservoir water.It is urgent to control the amount of nitrogen.

\section{REFERENCES}

[1] Yu Huiquan,Application of fuzzy comprehensive evaluation method in Water quality assessment of Yuyao River Reservior[J]. Journal of Water Resources and Water Engineering,2013,24(1) : 171-173,180

[2] Gao Hui,JinHui. Application of Fuzzy Comprehensive Evaluation Method in Water Quality Assessment of Shaping River Basin. Pearl River, 2005,26(6):50-51[J]

[3] Meng Xiangyu,Xu Deqian. Fuzzy Comprehensive Evaluation Model for the Assessment of Valley Water Quality and Its Application[J]..Environmental Protection Science, 2009, 35( 2) : 92-93.

[4] Qin Tianling,Hou Youze,Hao Cailian. Study on Water Quality valuation of Wulie River Basin Based on the Method of PCA[J]. Environmental Protection Science,2011,37(6) : 102-105
[5] Chen Shouyu,Li Yawei. Water quality evaluation based on fuzzy artificial neural network[J].. Advances In Water Science, 2005,16(1):88-91

[6] Zhou Linfei,Xu Shiguo.Application of Grey Clustering Method in Eutrophication Assessment of Wetland[J].. Journal of American Science,2006,2(4):53-58

[7] Xi Wenjuan,Jin Jing,Qian Hui. Application of improved fuzzy comprehensive evaluation method to water quality[J].. Journal of Water Resources and Water Engineering, 2012, 25(03) : 25-29

[8] Zhou Linfei,Gao Yunbiao, Xu Shiguo. Research on application of fuzzy mathematics to water quality evaluation of wetland[J]. Water Resources and Hydropower Engineering,2005,36(1):35-38

[9] Zhao Xiaoliang,Qi Qingjie,Li Ruifeng.Establishiment of the Assenssment Model for Drinking Water Quality of City Resource Based on the Fuzzy Mathematical Model. Earth and Environment,2013,41(1):71-76

[10] Xie Qun,Zhang Yubin,Sun Shengli. Seawater Quality Comprehensive Evaluation and Analysis in Liusha Bay. Environmental Monitoring in China,2011,27(1):77-83

[11] Song Ke,Zhao Sheng,Zhang Li.Fuzzy C omprehensive Assenssment on Water Quality of Larimichthys Crocea Mariculture Areas on Dongji. Oceanologia et Limnologia Sinica,2013,44 (2) : 383-388

[12] Xue kaixi,Hu yanxiang,Zhao zhongying. Dynastic Weight System of Hazard Assessment for Rainfall-induced Highway Landslides. Earth and Environment, 2011,39(3):11-14

[13] State Environmental Protection Administration, General Administration of Quality Supervision, Inspection and Quarantine .GB3838-2002 Surface Water Quality Standards[S]..Bei Jing: China Environmental Science Press,2002 